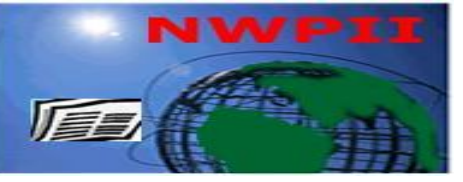

American Journal of Biomedical Sciences

ISSN: 1937-9080

nwpii.com/ajbms

\title{
Oxidative Stress and Stress-signaling in Chemoprevention of Early Colon Cancer by Diclofenac
}

\author{
Jasmeet Kaur and S N Sanyal*
}

Department of Biophysics, Panjab University, Chandigarh - 160 014, India

*Corresponding author

Dr S N Sanyal

Professor

Department of Biophysics

Panjab University

Chandigarh - 160014

India

Phone: +911722534122

Email: sanyalpu@gmail.com

Received: 30 July 2009; | Revised: 29 September 2009; | Accepted: 8 October 2009

\begin{abstract}
Role of oxidative stress and NF- $\mathrm{kB}$ signalling was evaluated in the chemopreventive effects of diclofenac, a dual cycloxygenase inhibitor in 1,2-dimethylhydrazine dihydrochloride (DMH)-induced colon carcinogenesis in rat model. After a 6 week long treatment with DMH (early stage), morphological analysis revealed marked occurrence of preneoplastic features such as multiple plaque lesions (MPLs), aberrant crypts (ACs) and aberrant crypt foci (ACF) in the colonic mucosa. Histologically well characterized dysplasia and hyperplasia were also observed. Simultaneous administration of diclofenac with DMH resulted in a significant reduction of these, proving the chemopreventive efficacy of diclofenac at the chosen dose. Diclofenac only group didn't show any prominent carcinogenic feature. The colonic mucosa showed decreased reactive oxygen species (ROS) generation, nitric oxide (NO) levels and inducible nitric oxide synthase (iNOS) expression in the DMH group. Apoptosis was quantified in the colonic mucosa by measuring caspase-1 and 3 activities and cleavage of PARP by Western blot analysis. Immunohistochemical localization of PARP was also done in colonic paraffin sections. The activities of both the caspases and cleavage of PARP decreased after DMH treatment. Also, the number of PARP positive cells was few in the $\mathrm{DMH}$ group, while it featured prominently in all the other groups. The expression of nuclear factor- $\mathrm{kB}$ (NF$\kappa \mathrm{B})$ and IкB kinase (IKK) was elevated while that of inhibitory $\kappa \mathrm{B}(\mathrm{I} \kappa \mathrm{B})$ reduced after DMH treatment, as assessed both by Western blot and immunohistochemistry. Diclofenac significantly altered the modulations induced by DMH in all the studied parameters, thus confirming the role of oxidative stress and signalling in its chemopreventive action.
\end{abstract}

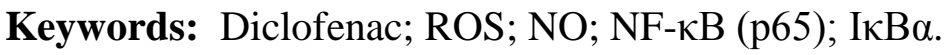




\section{Introduction}

Cellular redox changes have emerged as pivotal and proximal events in cancer [1]. Initially thought of as 'the evil', mainly because oxidative stress promotes DNA damage, redox changes may mediate cancer prevention by natural and pharmaceutical agents. Redox signalling has emerged as the concept that electron-transfer processes play a key messenger role in biological systems [2]. At the heart of redox signalling are the so-called reactive oxygen species (ROS), a term that includes oxygen radicals (e.g., $\mathrm{O}_{2}{ }^{--}$and $\left.\mathrm{OH}^{-}\right)$and also nonradical derivatives of $\mathrm{O}_{2}$ $\left(\mathrm{H}_{2} \mathrm{O}_{2}\right)$. The discovery of the reactive nitrogen species expanded this term to reactive oxygen and nitrogen species (RONS). Reactive oxygen and nitrogen species have 'multiple biological personalities'. At low concentrations they protect the cell and at higher concentrations they can damage many biological molecules, such as DNA, proteins and lipids. They may also help prevent cancer by initiating the death of the transformed cell. There is significant, although incomplete, evidence for a role of RONS in cancer, including genotoxicity, promotion of transformed cell growth and angiogenesis as well as regulation of apoptosis. RONS have been associated with the induction of apoptotic and necrotic cell death, the specific outcome depending, on the cellular levels of RONS. Moderately elevated levels of RONS initiate RONS signalling, such as through MAPKs (p38, JNK) [3], NF-кB, COX-2 [4], NOS [5] and Wnt [6], which can lead to apoptotic cell death. The redox-mediated cytokinetic effect of NOAcetyl salicyclic acid (ASA), which eliminates neoplastic cells, constitutes perhaps its major chemopreventive action against cancer [7].

$\mathrm{NF}-\mathrm{KB}$ has been shown to be required for NO production through inducible nitric oxide synthase (iNOS) induction in many cell types including hepatocytes [8], rodent macrophages [9] and vascular smooth muscle cells [10]. This transcription factor has also been implicated in the induction of pro-inflammatory genes encoding TNF- $\alpha$, IL- $1 \alpha$, IL-6 and COX-2 [11]. NF- $\mathrm{KB}$ is activated as a consequence of phosphorylation, ubiquitination and subsequent proteolytic degradation of I $\mathrm{K} B$ protein through activation of

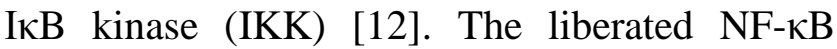
translocates into nuclei and binds as a transcription factor to $\mathrm{kB}$ motifs in the promoter of target genes, leading to the induction of iNOS mRNA expression and thus NO production.

Therefore, the present study was undertaken to determine the role of oxidative stress, redoxsensitive NF- $\mathrm{KB}$ and their association with mitochondrial apoptotic pathway in early stages of colon cancer and its chemoprevention with diclofenac, a non-steroidal anti-inflammatory drug with dual inhibitory role for both COX-1 and COX-2. In an earlier communication, we have shown the association of PI-3kinase and Wnt signaling in the diclofenac induced apoptosis in cancer cells [13].

\section{Materials and methods}

\subsection{Chemicals}

1, 2-dimethylhydrazine dihydrochloride $(\mathrm{DMH})$, Bradford reagent and 2,7dichlorofluorescein diacetate (DCFH-DA) were purchased from Sigma-Aldrich (St. Louis, MO, USA). $\quad$ N-acetyl-Tyr-Val-Ala-Asp-4methylcoumaryl-7-amide (YVAD-AMC), Nacteyl-Asp-Glu-Val-Asp-7-amino-4 methylcoumarin (DEVD-AMC) and 7-amino-4methycoumarin (AMC) were from MP Biomedicals (CA, USA). Primary antibody against

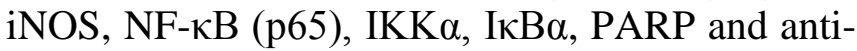
mouse $\beta$-actin were purchased from Santa Cruz Biotechnology Inc., CA (USA). Alkaline phosphatase-conjugated secondary antibodies and BCIP-NBT were purchased from Genei, Bangalore (India). Diclofenac was a generous gift from Ranbaxy. All other chemicals and reagents used in the present study were of analytical grade and procured from the Indian manufacturers.

\subsection{Animal procurement}

Male adult Sprague-Dawley rats of body weight between 100-120g were obtained from the inbred population of the Central Animal House, Panjab University, Chandigarh. These were acclimatized to the control diet (rodent chow) and water ad libitum for atleast 1 week. Animals were maintained as per the principles and guidelines of the Ethics Committee of Animal Care of Panjab 
University in accordance with the Indian National Law on animal care and use. The animals were housed three per cage in polypropylene cages with a wire mesh top and a hygienic bed of husk (regularly changed) in a well ventilated animal room till the end of the experimental period. The animals were also maintained under a $12 \mathrm{~h}$ photoperiod of light and darkness, respectively.

\subsection{Treatment schedule}

Animals were assorted into the following groups with four to six animals in each group:

Control Group, Vehicle Treated: Animals were administered the vehicle (1mM EDTA-saline subcutaneously (s.c.) in weekly injection and $0.5 \%$ carboxymethyl cellulose (CMC) per oral (p.o.) daily.

DMH Group: Animals were administered with DMH weekly at a dose of $30 \mathrm{mg} / \mathrm{Kg}$ body weight (s.c.), as had been established in our laboratory earlier [14]. DMH was freshly prepared in $1 \mathrm{mM}$ EDTA-saline, $\mathrm{pH}$ adjusted to 7.0 using dilute $\mathrm{NaOH}$ solution.

DMH + Diclofenac Group: Diclofenac was given daily per oral (p.o) at its therapeutic antiinflammatory dose $\left(\mathrm{ED}_{50}\right.$ for rats, $8 \mathrm{mg} / \mathrm{kg}$ body weight) to the animals along with the weekly administration of DMH. The anti-inflammatory dose of diclofenac had been chosen from the work of Winter et al. 1962 [15], following the carrageenan-induced paw oedema model in the rat hind leg.

Diclofenac Group: Diclofenac alone was administered p.o daily ( $8 \mathrm{mg} / \mathrm{kg}$ body weight).

After six weeks, animals were kept on overnight fasting with drinking water ad libitum and sacrificed the next day. The animal body weights in all the groups were recorded once in a week till the termination of the experiment.

\subsection{Tissue pathology}

The colons were removed and flushed clear with ice-cold physiological saline $(\mathrm{NaCl}$ solution, $9 \mathrm{~g} / \mathrm{L})$. These were opened longitudinally along the median and laid flat to examine the incidence of macroscopic neoplastic lesions/plaques called the multiple plaque lesions (MPLs). The colons were divided into proximal, medial and distal segments for the examination.

\subsection{Aberrant crypt foci (ACF) analysis}

The colons were removed, flushed clean, cut open and divided into different parts as above. After a minimum of $24 \mathrm{hrs}$ fixation in $10 \%$ buffered formalin, the colons were stained with $0.2 \%$ methylene blue in Krebs Ringer solution for 5-10 min [16]. The mucosal surface of the colon was evaluated for the number of aberrant crypts (AC) and aberrant crypt foci (ACF) in the stained colon under 40X magnification using a light microscope. Enlarged and slightly elevated lesions with increased staining were readily identifiable in comparison to normal adjacent mucosa. These lesions were classified as single enlarged crypts or foci containing two or more abnormal crypts.

\subsection{Histopathological analysis}

Colon pieces removed from the sacrificed rats were immediately fixed in $10 \%$ buffered formalin for $24 \mathrm{hrs}$. The tissues were dehydrated in ascending series of alcohol and kept in 1:1 mixture of absolute alcohol and benzene for $1 \mathrm{hr}$. For embedding the tissues in wax, they were kept in benzene for 40-45 min and transferred sequentially to $1: 1$ benzene and wax mixture at $60^{\circ} \mathrm{C}$ for $1 \mathrm{hr}$ and then pure wax for $6 \mathrm{hr}$ at $60^{\circ} \mathrm{C}$ with two changes. The tissues were embedded in wax and five micron thick sections were cut using a hand driven microtome and transferred to the egg albumin coated slides. Sections were then dewaxed in xylene, stained in hematoxylin and eosin, mounted in DPX and viewed under a light microscope and photographed.

\subsection{Western blot analysis}

Protein samples/nuclear extracts $(100 \mu \mathrm{g})$ from each treatment group were separated on $10 \%$ SDS-PAGE. The separated proteins were electrophoretically transferred to nitrocellulose membrane (Genei, Bangalore, India). Immunoblot was prepared using primary antibodies (iNOS 1:500, NF-кB (p65) - 1:1000, IKK $\alpha$ - 1:1000, IкB $\alpha$ - 1:1000, PARP - 1:1000) from Santa Cruz Biotechnology Inc., CA (USA) and alkaline phosphatase-conjugated respective secondary antibodies at a dilution of 1:10, 000 (Genei, Bangalore, India). BCIP-NBT detection system was used to develop the blot. Bands obtained were densitometrically analyzed using Image J software 
and the density expressed as gray values in densitometric units.

For preparation of protein extracts, colons were removed and rinsed from the different treatment groups after completion of 6 weeks. Total lysates were prepared in fresh ice-cold protein lysis buffer $(10 \mathrm{mM}$ Tris, $100 \mathrm{mM} \mathrm{NaCl}$, $5 \mathrm{mM}$ EDTA, $1 \%$ Triton-X100, 1mM PMSF and $2 \mathrm{mM}$ DTT (pH 8)). The extracts were cleared by centrifugation at $10,000 \mathrm{rpm}$ for 10 minutes at $4^{\circ} \mathrm{C}$. The supernatants were collected as the total lysate. For nuclear extract, the nuclei were suspended at $0-4^{\circ} \mathrm{C}$ in $50 \mathrm{mM} \mathrm{NaCl}, 10 \mathrm{mM}$ Hepes, pH 7.6, 0.1 mM EDTA, 25\% glycerol and $0.5 \mathrm{mM}$ PMSF and pelleted by centrifugation in an eppendorf centrifuge at 5,000 rpm for $15 \mathrm{~min}$ at $4^{\circ} \mathrm{C}$. Resulting nuclear debris were incubated in the same buffer for $30 \mathrm{~min}$ on ice, centrifuged at $10,000 \mathrm{rpm}$ at $4^{\circ} \mathrm{C}$ for 10 minutes and the resultant supernatant was used as the nuclear extract in the present study. Protein concentration was determined by the method of Bradford [17].

\subsection{Immunohistochemical localization studies}

$5 \mu \mathrm{m}$ thick paraffin sections of rat colon were deparaffinized in two changes of xylene for 10 min each. The sections were then gradually hydrated and brought to water. The non specific staining was blocked by incubating the sections with 2\% BSA in phosphate buffered saline (PBS $10 \mathrm{mM}, \mathrm{pH} 7.2)$. The sections were then incubated with polyclonal antibodies against iNOS - 1:500, NF- $\kappa \mathrm{B}(\mathrm{p} 65)$ - 1:1000, IKK $\alpha$ - 1:1000, ІкB $\alpha-$ 1:1000 and PARP - 1:1000 in a moist chamber for $2 \mathrm{hr}$ at $37^{\circ} \mathrm{C}$. After incubation, the sections were washed in PBS, PBS Tween (PBS with $0.05 \%$ Tween-20) and PBS successively for 5 min each. The sections were then incubated with respective alkaline phosphatase-labeled secondary antibodies $(1: 10,000)$ for $2 \mathrm{hr}$. Sections were washed again in the same manner as described above and the reaction product was developed using BCIP-NBT. Reaction was terminated by washing with distilled water after which sections were counterstained with methyl green and mounted in DPX.

\subsection{Microscopy and Data analysis}

Am. J. Biomed. Sci. 2010, 2(1), 63-78; doi: 10.5099/aj100100063
Sections were viewed and photographed at 200X with a Leica Optiphot microscope to which was attached a Leica Digital camera.

\subsection{Caspase-1 (ICE) and Caspase-3 (CPP32) enzyme activity}

The activities of the caspase-1 and caspase-3like proteases were assayed by measuring the proteolytic cleavage of the fluorogenic substrates. N-acetyl-Tyr-Val-Ala-Asp-4-methylcoumaryl-7amide (YVAD-AMC) is preferentially cleaved by members of the ICE family of caspases (Caspase1) and N-acteyl-Asp-Glu-Val-Asp-7-amino-4methylcoumarin (DEVD-AMC) is cleaved by the CPP32 family of caspases (Caspase 3). $2 \times 10^{6}$ isolated colonocytes were lysed in lysis buffer (1\% Triton X-100, 0.32M sucrose, 5mM EDTA, $1 \mathrm{mM}$ PMSF, $1 \mu \mathrm{g} / \mathrm{ml}$ aprotinin, $1 \mu \mathrm{g} / \mathrm{ml}$ leupeptin, $2 \mathrm{mM}$ DTT, $10 \mathrm{mM}$ Tris/ $\mathrm{HCl}, \mathrm{pH} 8$ ) for $15 \mathrm{~min}$ at $4^{\circ} \mathrm{C}$, followed by ultrasonication for complete disruptions of the cells and centrifugation (20,000g, 5min). Caspase-1 and caspase-3 like protease activity was detected in the resulting supernatant by measuring the proteolytic cleavage of the respective fluorogenic substrates at $50 \mu \mathrm{M}$ final concentration in the assay buffer $(100 \mathrm{mM}$ Hepes, $10 \%$ sucrose, $0.1 \%$ CHAPS pH 7.5, $1 \mathrm{mM}$ PMSF, $1 \mu \mathrm{g} / \mathrm{ml}$ aprotinin, $1 \mu \mathrm{g} / \mathrm{ml}$ leupeptin, $2 \mathrm{mM}$ dithiothreitol). Standards containing AMC (0$1000 \mathrm{pmol}$ ) were used to determine the amount of fluorochrome released. Fluorescence recordings were done using an excitation wavelength of $400 \mathrm{~nm}$ versus an emission wavelength of $505 \mathrm{~nm}$ [18]. The specific activity of each caspase was calculated in terms of pmoles of AMC produced per $\mathrm{mg}$ of protein per minute.

\subsection{Reactive oxygen species}

Intracellular level of ROS was estimated using the fluorescent probe, 2,7dichlorofluorescein diacetate (DCFH-DA). Method of LeBel et al. 1992 [19] was followed for estimating the generation of ROS in the present study. 2 x $10^{6}$ isolated colonocytes were suspended in phosphate buffered saline (PBS, pH 7.4), DCFH-DA was added at a final concentration of $2.5 \mu \mathrm{M}$ and incubated at $37^{\circ} \mathrm{C}$ for $60 \mathrm{~min}$ in dark. Cells were pelleted by centrifugation at $5000 \mathrm{rpm}$ and resuspended in 
PBS. DCF fluorescence intensity was detected with excitation wavelength at $485 \mathrm{~nm}$ and emission wavelength at $530 \mathrm{~nm}$, which is proportional to the amount of ROS, formed intracellulary.

\subsection{Nitric oxide (NO) assay}

Nitric oxide production was estimated by measuring nitrite, a stable metabolic product of NO, using Griess reagent [20]. To $100 \mu l$ of the sample, $100 \mu 1$ of Griess reagent (1:1 ratio of $0.1 \%$ n-Naphthyl ethylenediamine dihydrochloride solution in distilled water and $1 \%$ Sulphanilamide in $2.5 \%$ orthophosphoric acid) was added in an ELISA strip. The ELISA strip was incubated in dark for $10 \mathrm{~min}$ at room temperature, the pink color so observed was read for its absorbance at $540 \mathrm{~nm}$ in an Elisa Reader. Concentrations were determined from a linear standard curve prepared by using $10 \mathrm{mM}$ stock solution of the sodium nitrite (1.25nmoles-10nmoles). The results were expressed as nmoles of nitrite formed per $\mathrm{mg}$ protein.

\subsection{Statistical analysis}

Table1: Chemopreventive response of diclofenac in terms of multiple plaque lesions (MPLs), aberrant crypts (ACs) and aberrant crypt foci (ACF) in DMH-induced colon carcinogenesis for six weeks

\begin{tabular}{|c|c|c|c|c|}
\hline Groups & MPLs/colon & MPL incidence (\%) & $\begin{array}{c}\text { Aberrant crypts/100 } \\
\text { crypts }\end{array}$ & $\begin{array}{c}\text { Aberrant crypt } \\
\text { foci/colon }\end{array}$ \\
\hline Control & Nil & 0 & Nil & Nil \\
\hline DMH & $5.58 \pm 0.75^{\mathrm{c}}$ & 100 & $53.50 \pm 1.29^{\mathrm{c}}$ & $18.00 \pm 1.82^{\mathrm{c}}$ \\
\hline DMH + Diclofenac & $2.00 \pm 0.63^{\mathrm{c} / \mathrm{f}}$ & 33.3 & $21.75 \pm 1.70^{\mathrm{c} / \mathrm{f}}$ & $5.00 \pm 0.82^{\mathrm{c} / \mathrm{f}}$ \\
\hline Diclofenac & Nil & 0 & $\mathrm{Nil}$ & $\mathrm{Nil}$ \\
\hline
\end{tabular}

MPL incidence $=$ the percentage of animals having MPLs

The values are Mean \pm S.D. of 6 animals for Multiple Plaque Lesions (MPLs) and of 4 animals for Aberrant crypt foci $(\mathrm{ACF})$, respectively.

${ }^{\mathrm{c}} \mathrm{p}<0.001$ in comparison to control and ${ }^{\mathrm{f}} \mathrm{p}<0.001$ in comparison to DMH by one way ANOVA.

Aberrant crypts (ACs) were identified as the crypts that were two to three times larger than the surrounding normal crypts; with increased methylene blue staining due to a thickened layer of epithelial cells; slit-shaped lumina and microscopically elevated above the plane of normal crypts. ACFs were distinct aggregations of these abnormal crypts. ACs and ACF frequencies were significantly higher in the DMH treated rats (Table 1 and Figure 1b). Colonic mucosa from control and diclofenac only groups was free from aberrant crypts. Simultaneous administration of 
diclofenac with DMH reduced these features significantly.

Figure 1c shows the histopathological evaluation of the colonic tissue from the different groups where the DMH treated animals exhibited severe dysplasia of the crypt cells with nuclei enlarged, round or ovoid and deeply stained. The number of mitotic cells is far more and the number of mucin producing goblet cells markedly reduced. The control animals showed intact crypt architecture, large number of goblet cells and clear submucosa. The crypts are interspersed in the connective tissue layer, while stroma and the stretches of muscularis mucosa also prominently visible. It is important to note that the mucosal epithelium in the $\mathrm{DMH}+$ diclofenac group showed much less dysplastic changes, although the crypt morphology still found to be compromised. In diclofenac alone, mild hyperplasia was observed with the crypts assuming normal features.

(a)

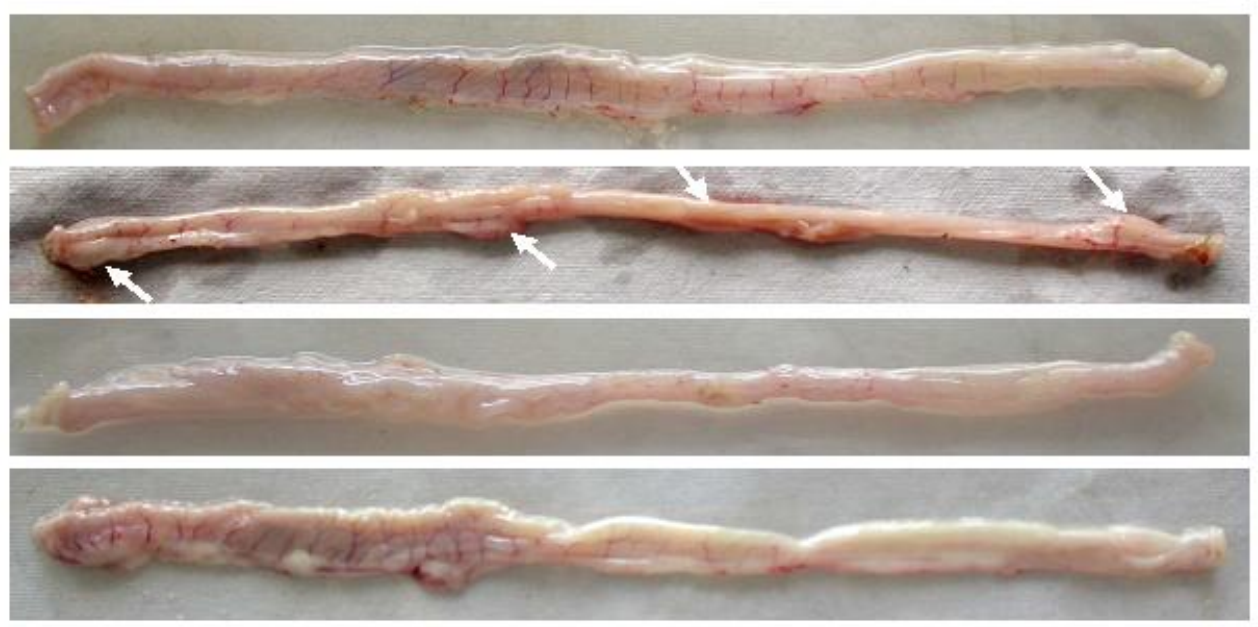

\section{Control}

\section{DMH}

DMH + Diclofenac

\section{Diclofen ac}

(b)
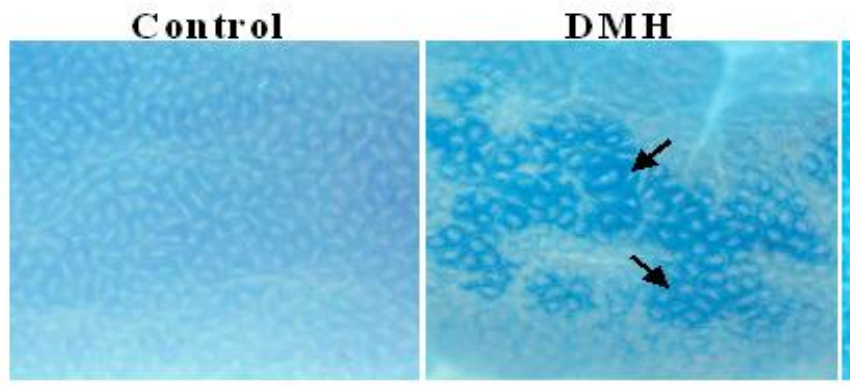

DMH + Diclofenac

Diclofenac

(c)
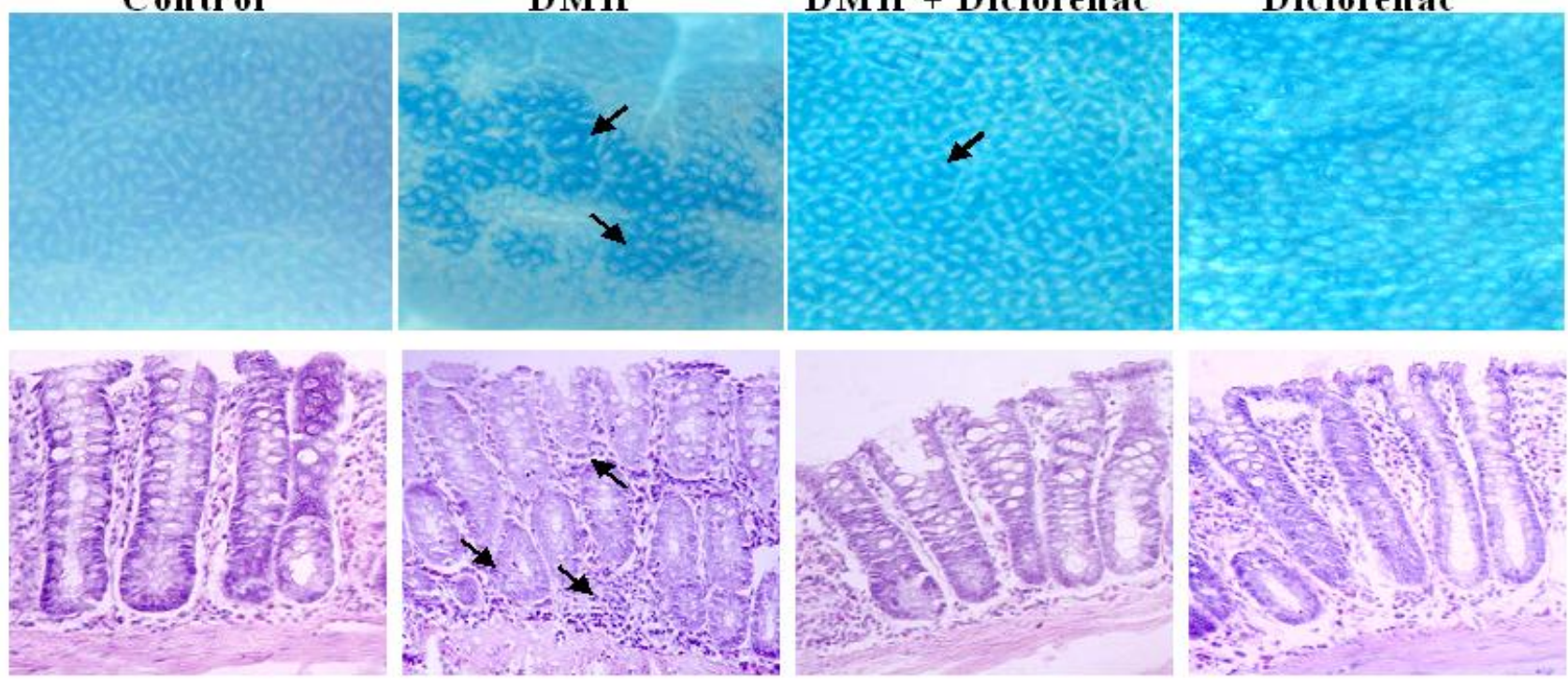

Figure 1: (a) Intact colons showing the occurrence of MPLs (arrows) after six weeks of DMH treatment as compared to control and diclofenac only groups and effect of co-administration of diclofenac on these. (b) Photomicrographs showing aberrant crypts and aberrant crypt foci (arrows) from each group at 40X. (c) Photomicrographs (200X) showing the histopathological changes after DMH and diclofenac treatment alone and in combination. 


\subsection{Oxidative alterations}

Generation of ROS and thus oxidative stress is known to activate the cell death machinery. Therefore, we examined the levels of ROS after DMH treatment and possible effect of diclofenac co-administration on it. We determined the levels of ROS in isolated colonocytes loaded with the fluorescent probe, DCFH-DA. DCFH-DA derived fluorescence was found to be decreased after DMH treatment. Co-administration of diclofenac with DMH significantly increased the fluorescence intensity indicating that diclofenac increased intracellular levels of ROS such as $\mathrm{H}_{2} \mathrm{O}_{2}$ and perhaps other peroxides and also $\mathrm{O}_{2}{ }^{-}$(Figure 2a).

(a)

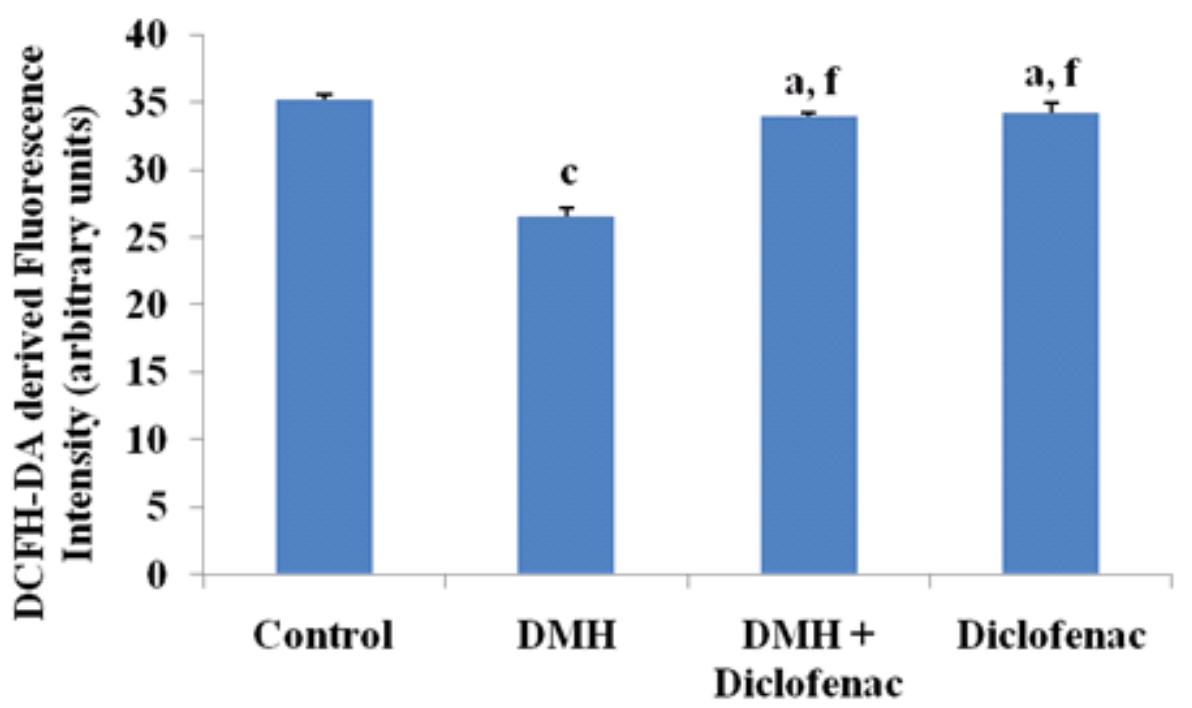

(b)

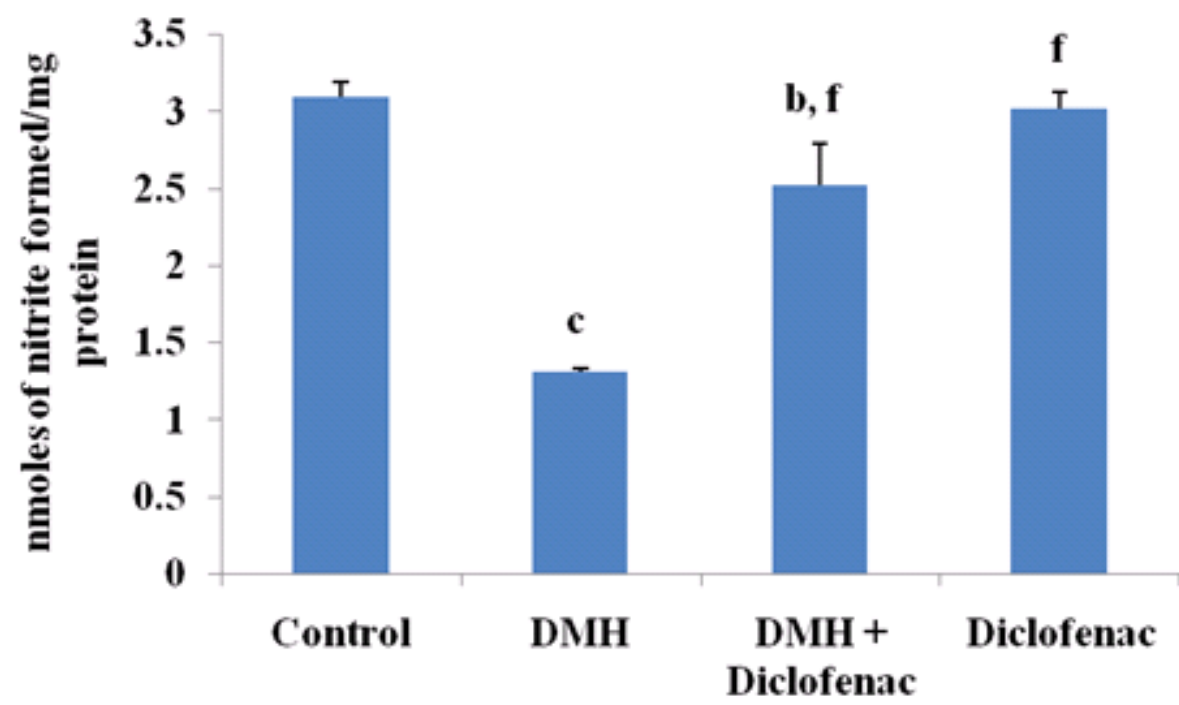

Figure 2: (a) Fluorescence intensity indicating the generation of ROS, as measured by DCFH-DA method in each group. (b) Nitric oxide (NO) production, estimated in the colonic mucosa using Greiss reagent in each group. The 
values are Mean \pm S.D. of 4 animals. ${ }^{a} p<0.05,{ }^{b} p<0.01,{ }^{c} p<0.001$ in comparison to control and ${ }^{f} p<0.001$ in comparison to DMH by one way ANOVA.

NO is a highly reactive molecule with dichotomous regulatory roles in biological events. Consistent with the observed decrease in ROS levels, there was a significant decrease in nitric oxide levels after DMH treatment (Figure 2b). This oxidative alteration in colonic mucosa was ameliorated by the co-administration of diclofenac with $\mathrm{DMH}$, which manifested as the significant increase in NO levels comparable to control and diclofenac only groups.

\subsection{Inflammatory signaling}

$\mathrm{NF}-\kappa \mathrm{B}$ is a sequence-specific transcription factor known to be involved in inflammatory responses and recently in tumorigenesis. Therefore the possibility that diclofenac-induced apoptosis was attributable to the suppression of NF- $\kappa B$ was considered. Nuclear levels of NF- $\kappa$ B (p65) proteins were evaluated by Western blot in colonic samples. Rats of DMH group exhibited higher levels of nuclear NF- $\kappa \mathrm{B}$ (p65) than those of $\mathrm{DMH}$ + diclofenac group, diclofenac only group and control group (Figure 3a). Results from immunohistochemistry illustrate intense nuclear staining of colonocytes after DMH treatment, whereas a low expression was seen in all the other groups, primarily cytoplasmic in goblet cells (Figure 3c).

Translocation of $\mathrm{NF}-\kappa \mathrm{B}$ to the nucleus is normally regulated by $\mathrm{I} \kappa \mathrm{B} \alpha$ degradation. We examined whether the inhibition of $N F-\kappa B$ by diclofenac was due to decreased degradation of

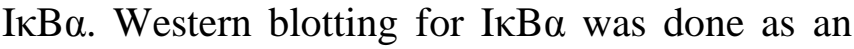
index of total inhibitor expression levels. DMH group showed decreased levels of $\mathrm{I} \kappa \mathrm{B} \alpha$ as compared to the control and diclofenac only groups. Diclofenac co-administration however prevented the degradation of $\mathrm{I} \kappa \mathrm{B} \alpha$ significantly (Figure 3a). Immunohistochemical staining showed that $\mathrm{I} \kappa \mathrm{B} \alpha$ expression was reduced and restricted only to goblet cells after $\mathrm{DMH}$ treatment, whereas a high expression of $\mathrm{I} \kappa \mathrm{B} \alpha$ was seen in colonocytes as well as in stromal cells in control and diclofenac only groups. Diclofenac coadministration with $\mathrm{DMH}$ was able to increase the
$\mathrm{I} \kappa \mathrm{B} \alpha$ staining, however still limited to goblet cells and few stromal cells (Figure 3c).

I $\kappa \mathrm{B} \alpha$ phosphorylation and consequently its degradation are governed by I $\mathrm{B}$ kinase $\alpha(\mathrm{IKK} \alpha)$ and thus IKK $\alpha$ appears to be critical for NF- $\kappa B$ activation. Both Western blot analysis and immunohistochemistry results indicate increased expression of IKK $\alpha$ in the colonic mucosa from DMH treated animals (Figure $3 \mathrm{a}$ and $3 \mathrm{c}$ ). The level of expression was reduced both in protein extracts and paraffin section after diclofenac coadministration with DMH. Only goblet cells were seen to be expressing IKK $\alpha$ in the control, DMH + diclofenac and diclofenac only groups, however DMH groups showed a high expression equally distributed in all the cell types. These results are indicative that diclofenac suppressed NF- $\kappa \mathrm{B}$ expression by inhibiting phosphorylation and degradation of $\mathrm{I} \kappa \mathrm{B} \alpha$ by IKK $\alpha$.

Expression of inducible nitric oxide synthase (iNOS) is a critical factor in both normal and pathogenic conditions as its expression results in high level of NO production. Further, nitric oxide and iNOS are involved in a feedback regulation mechanism. Therefore, to investigate the effect of iNOS expression on NO levels or vice versa, we studied the expression of iNOS by Western blot analysis and immunohistochemistry (Figure 3a and $3 \mathrm{c}$ ). The level of iNOS was found to be decreased after $\mathrm{DMH}$ treatment and increased after $\mathrm{DMH}+$ diclofenac treatment considerably. It is possible that this reduced expression of iNOS was responsible for the reduced NO levels after DMH treatment to rats.

\subsection{Pro-apoptotic changes}

Activation of caspases during apoptosis and their correlation with the cleavage and activation/inactivation of a range of critical cellular substrates, including activation of the DNA repair enzyme known as PARP is central to the apoptotic event. Potential effect of diclofenac on the activity of caspase- 1 and caspase- 3 and cleavage of PARP in the colonic mucosa was therefore explored. To identify changes in caspase-1 and caspase-3 activity, proteolytic 
cleavage of fluorogenic substrates were assayed. Western blotting and immunohistochemistry for PARP were done to assess PARP cleavage and expression, respectively. A decrease in the activities of the caspases (Figure 4a), PARP cleavage (Figure $4 \mathrm{~b}$ ) and PARP positive cells (Figure 4d) were observed after DMH treatment for six weeks. A significant increase in the activities of caspases, PARP cleavage and expression occurred after diclofenac was coadministered with DMH. This indicates that diclofenac is activating mitochondrial pathway to render pro-apoptotic effects against carcinogenic changes induced by DMH. 


\section{Figure 3}

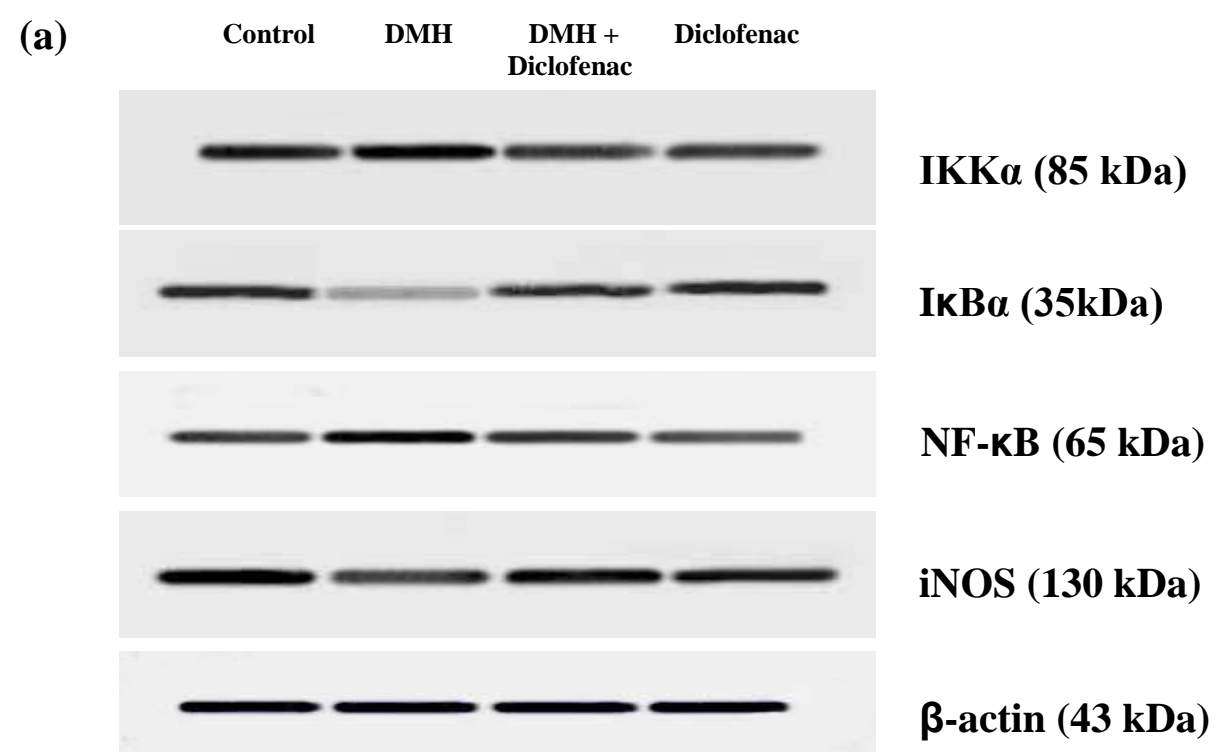

(b)

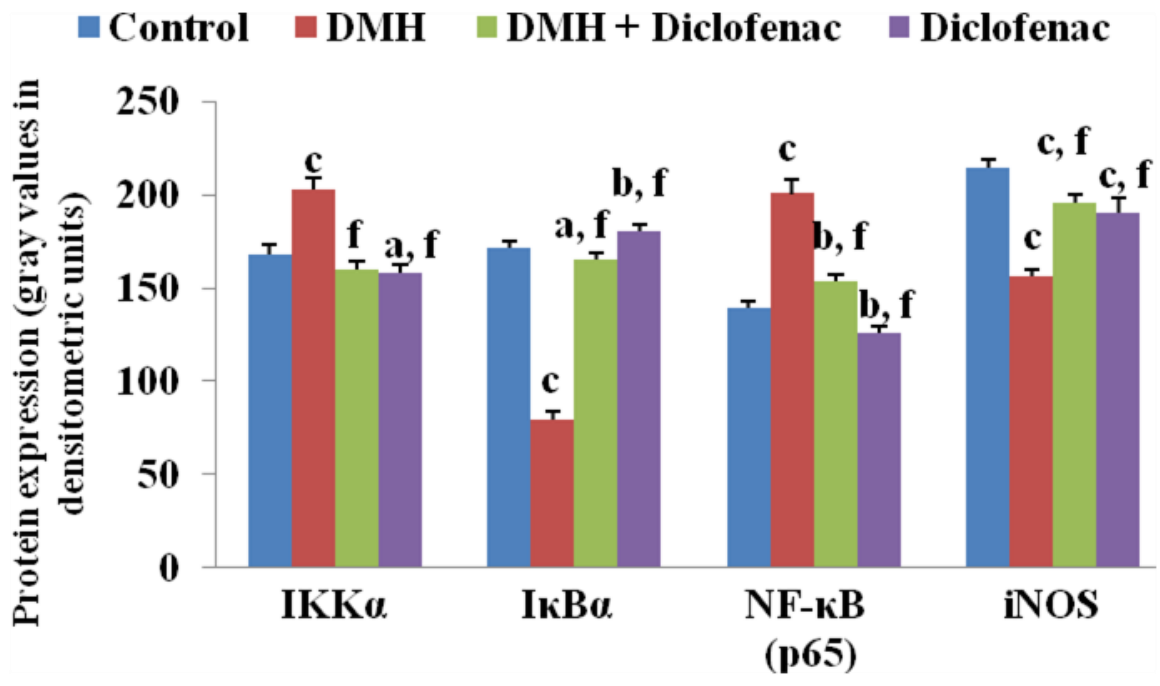


(c)

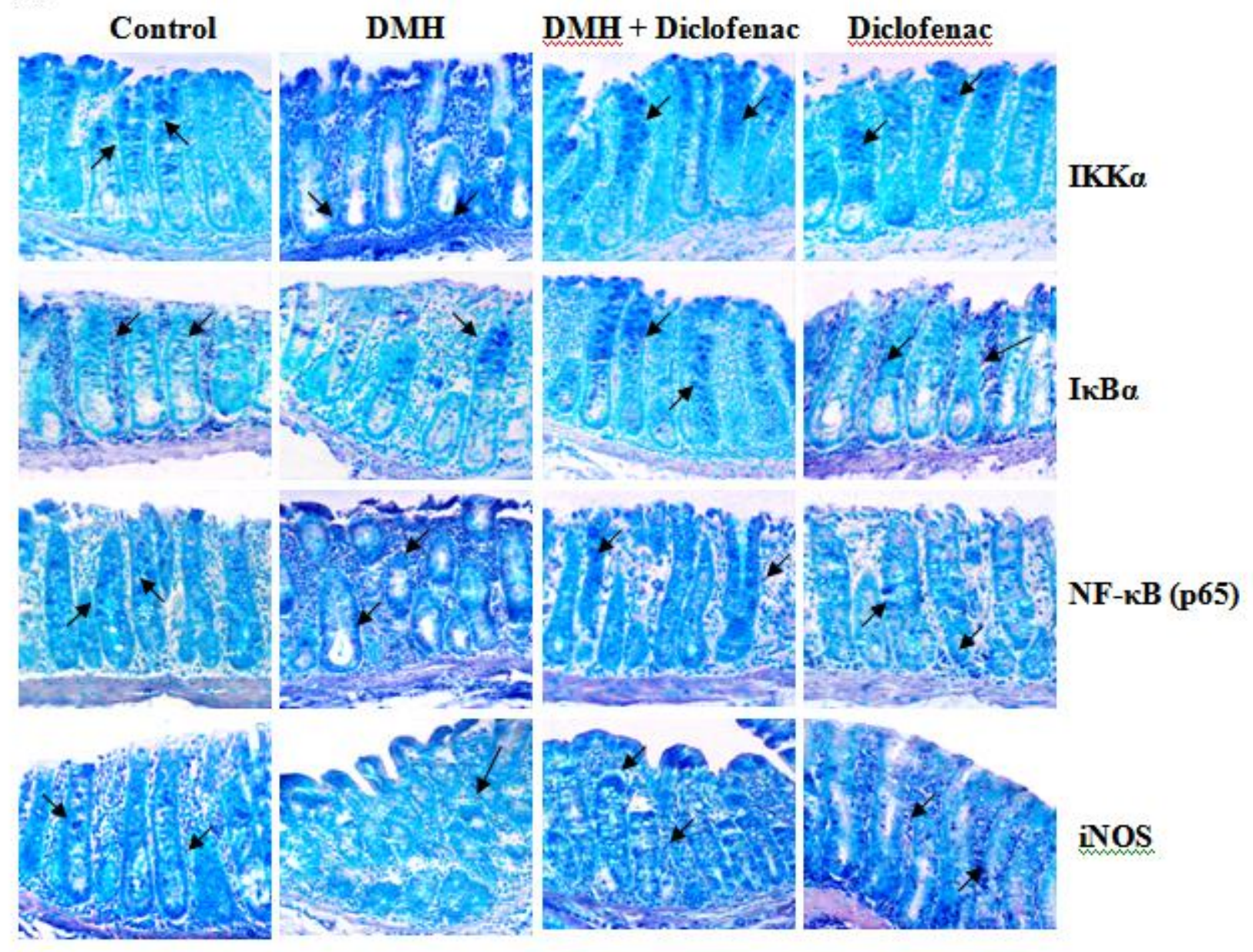

(d)

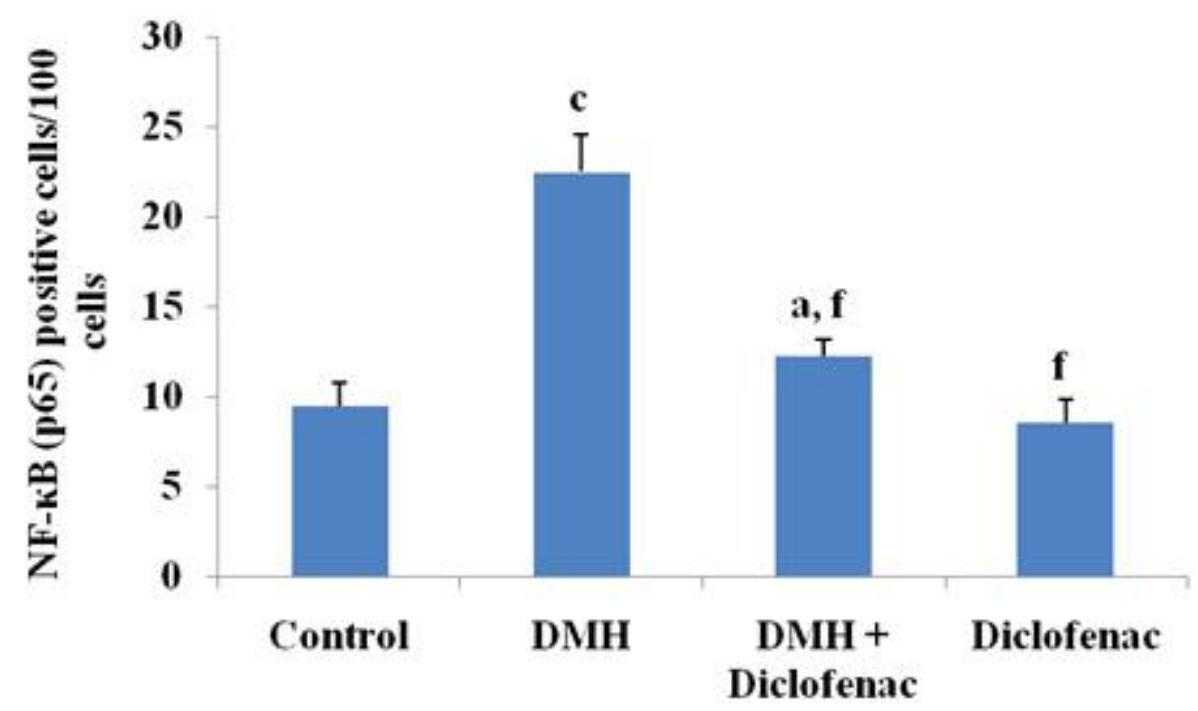

Figure 3: Western blot analysis for IKK $\alpha$, I $\mathrm{kB} \alpha, \mathrm{NF}-\mathrm{kB}$ (p65) and iNOS (a) and its densitometric analysis from each group (b). Photomicrographs showing the immunohistochemical localization (arrows) of IKK $\alpha, \mathrm{I} \mathrm{I} B \alpha, \mathrm{NF}-\mathrm{\kappa B}$ (p65) and iNOS (c) and counting of NF-kB (p65) positive cells (d) from each group. BCIP/NBT gave dark blue color while counterstain with methyl green stained the sections light green or cyan. The values are Mean \pm S.D. of 4 animals. ${ }^{a} \mathrm{p}<0.05,{ }^{b} \mathrm{p}<0.01,{ }^{c} \mathrm{p}<0.001$ in comparison to control and ${ }^{\mathrm{f}} \mathrm{p}<0.001$ in comparison to DMH by one way ANOVA. 


\section{Figure 4}

(a)

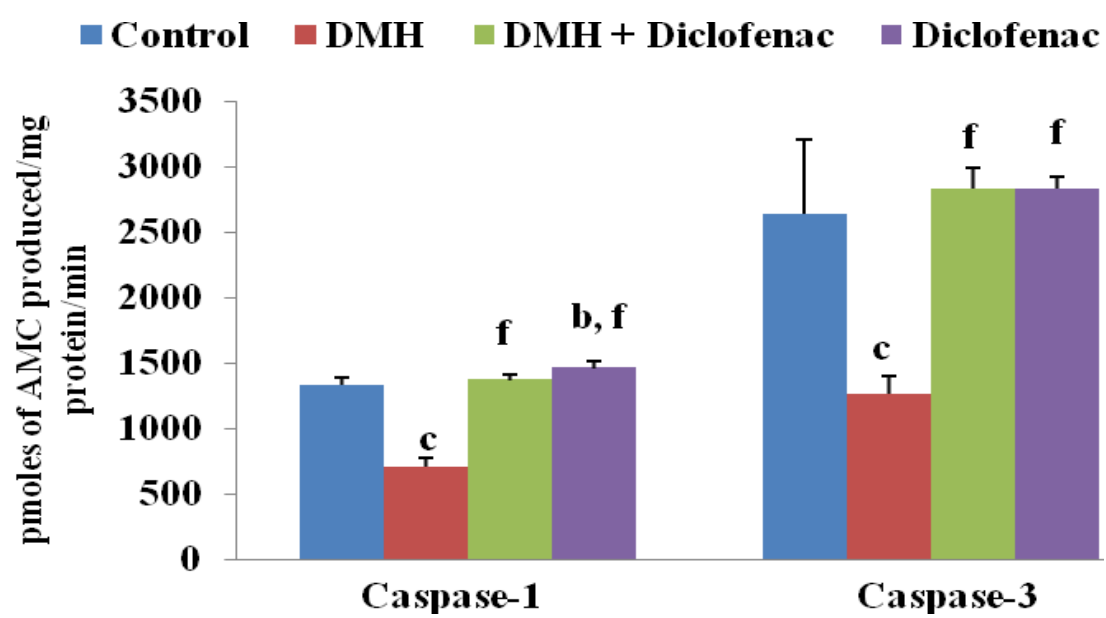

(b)

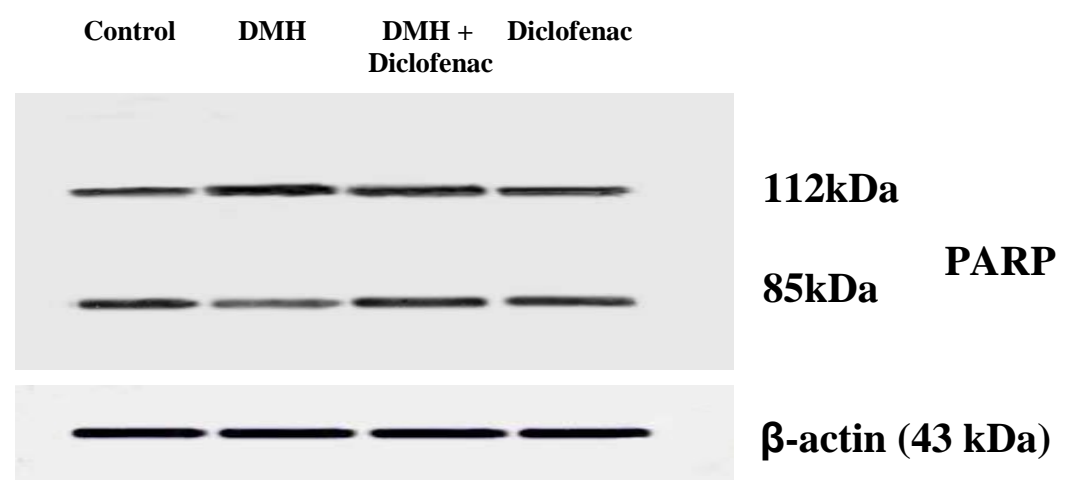

(c) $\quad$ Control $\square$ DMH $\square$ DMH + Diclofenac $\square$ Diclofenac

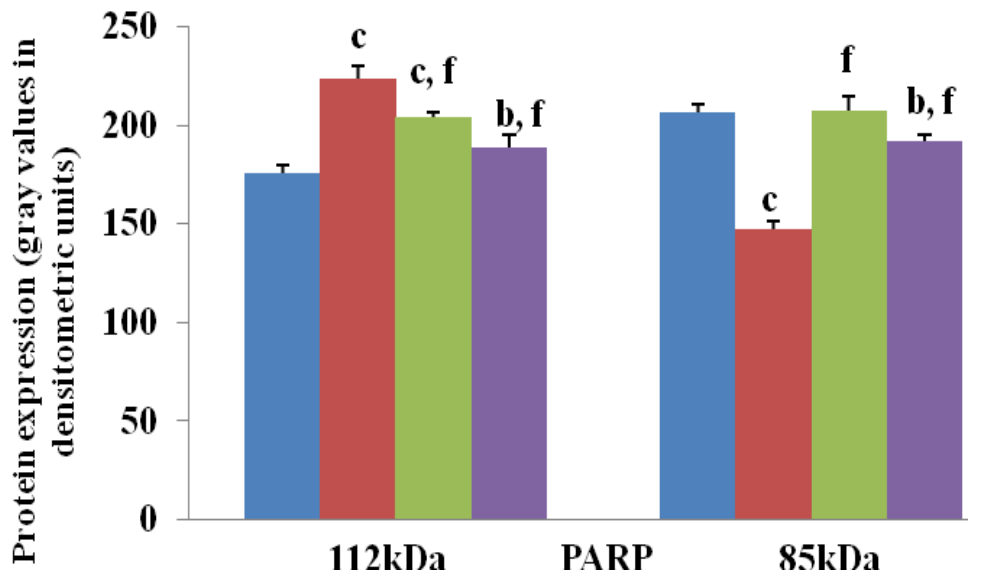




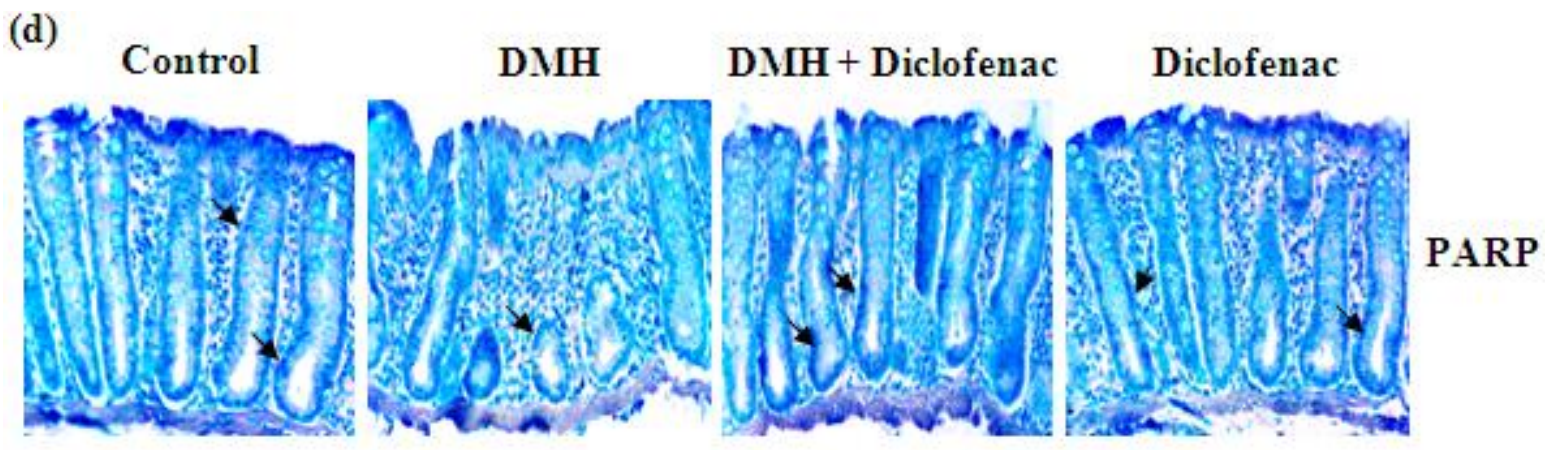

(e)

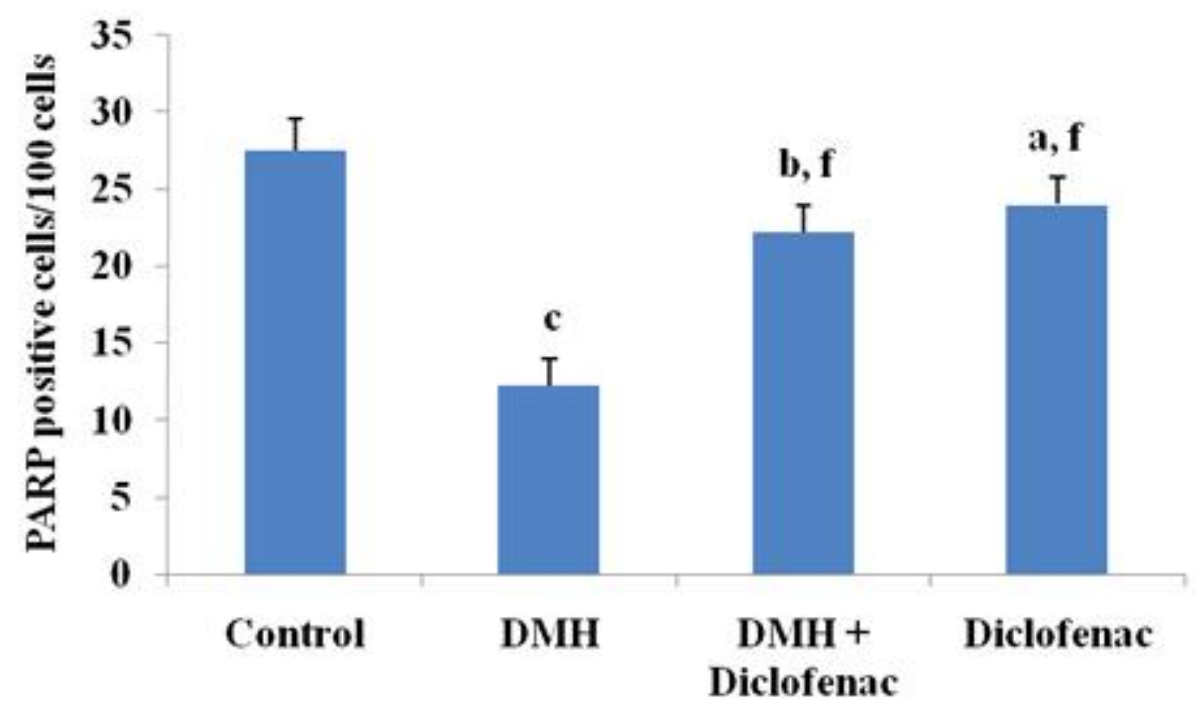

Figure 4: Effect of DMH and diclofenac treatment alone and in combination on the activities of caspase-1 and caspase-3 (a). Western blot analysis of PARP cleavage (b) and its densitometric analysis (c) from each group. Photomicrographs showing the immunohistochemical localization (arrows) of PARP (d) and counting of PARP positive cells (e) from each group. The values are Mean \pm S.D. of 4 animals. ${ }^{a} p<0.05,{ }^{b} p<0.01,{ }^{c} p<0.001$ in comparison to control and ${ }^{\mathrm{f}} \mathrm{p}<0.001$ in comparison to DMH by one way ANOVA.

\section{Discussion}

The present study was carried out to study the oxidative modulation during early stages of colon cancer and its role in chemoprevention by diclofenac. Further, redox-sensitive transcription factor, NF- $\mathrm{kB}$ and its activation was also studied.

The initiation of colon cancer is thought to begin with a single mutational event within an isolated aberrant colon crypt. The aberrant crypt foci are seen as an early precursor stage to adenomas and cancer [21]. Thus ACF number is a reliable biomarker of early colon cancer. Also, the rodent ACF assay is a powerful screening tool for the preclinical identification of the chemopreventive agents with very high specificity and sensitivity [22]. DMH treatment led to a marked increase in the grossly visible multiple plaque lesions (MPLs), aberrant crypts (ACs) and aberrant crypt foci (ACF) after six weeks of treatment. Histopathologically also, there was seen marked dysplasia as well as hyperplasia. Oral administration of diclofenac was able to weaken 
these features prominently indicating its efficiency as a chemopreventive agent at the present dose.

ROS are thought to play multiple roles in tumor initiation, progression and maintenance. ROS promotes cell growth under non-stress conditions whereas it appears to activate and modulate apoptosis when cells are under stress [23]. In addition, ROS can act directly on the apoptotic machinery, by accelerating mitochondrial depolarization and dysfunction during the effector phase of apoptosis [24]. In the present study, decreased ROS levels may be responsible for the low levels of apoptosis observed in the DMH group as determined by caspase- 1 and 3 activity and PARP cleavage and immunohistochemical expression. Chung et al. 2003 demonstrated that ROS production decreased mitochondrial membrane potential, release of cytochrome $\mathrm{c}$ and activation of caspases [25]. Increased activity of caspase- 1 and 3 and cleavage of PARP along with its increased expression in tissue sections after diclofenac co-administration may point to as how ROS mediated chemopreventive effects may occur in the present study.

NO can promote apoptosis (pro-apoptotic) in some cells, whereas it inhibits apoptosis (antiapoptotic) in other cells [26]. The factors affecting cell-specific sensitivity to NO-mediated apoptosis can be associated with the redox state within the cells, activation of the apoptotic signaling cascade (such as caspases) [27], the mitochondrial cytochrome c release [28], or apoptotic gene expression [29]. The oxidative environment observed in the present study after diclofenac coadministration with DMH may have sensitized the abnormal cells to undergo NO-mediated apoptosis. iNOS, one of the three nitric oxide synthases is constitutively expressed in some tissue [30] and its expression results in sustained and high level of NO production [31]. The different levels of NO in the DMH and DMH + diclofenac groups may be accredited to the differential expression of iNOS in these groups. Numerous studies have shown that NO possesses anti-tumor effects and that forced expression of iNOS causes regression of tumors $[32,33]$. As NO and iNOS are part of a feedback mechanism, our results indicate a positive feedback regulatory mechanism between them.

NO-Aspirin (NO-ASA), the most promising agent currently approved for cancer clinical trials by the Food and Drug administration (FDA) inhibited important signalling cascades, including $\mathrm{NF}-\kappa \mathrm{B}$ [7]. This prompted us to study NF- $\kappa \mathrm{B}$ activation/inhibition and its mechanism in the present study. Diclofenac inhibited nuclear translocation of the NF- $\kappa \mathrm{B}$ (p65) and degradation, phosphorylation and ubiquitination of $\mathrm{I} \kappa \mathrm{B} \alpha$ by IKK $\alpha$ when administered alongwith DMH. The data indicate that diclofenac-mediated elevated NO levels may had suppressed the anti-apoptotic effects of NF- $\kappa \mathrm{B}$ by inhibiting the posttranslational modification of $\mathrm{I} \kappa \mathrm{B} \alpha$. Accordingly, diclofenac represents a potential chemopreventive candidate for targeting the $\mathrm{I} \kappa \mathrm{B} \alpha-\mathrm{NF}-\kappa \mathrm{B}$ pathway in colon cancer.

Aberrant proliferation and impairment of apoptosis, a distinct form of cell death with defining morphologic and biochemical characteristics, including membrane blebbing, chromatin condensation, caspase activation and nuclear fragmentation [34], are both critical to oncogenesis and to the pathogenesis of cancer. In view of the importance of $N F-\kappa B$ activated pathways in proliferative and anti-apoptotic responses [35], agents that suppress these pathways are anticipated to be useful in the prevention and/or treatment of cancer. Death attributed to the suppression of NF- $\kappa \mathrm{B}$ activity has been reported to be associated with the activation of caspase-3-like proteases and cleavage of PARP $[36,37]$. In agreement with this, diclofenac coadministration was observed to suppress NF- $\kappa \mathrm{B}$ (p65) expression and induce apoptosis (induction of caspase-1 and caspase-3, and PARP cleavage) in the present study.

We conclude that oxidative stress and NO mediated the apoptotic effects of diclofenac in the present study by activating the caspases and PARP cleavage. I $\kappa \mathrm{B} \alpha-\mathrm{NF}-\kappa \mathrm{B}$ pathway was also significantly modulated after DMH administration and played a crucial role in diclofenac induced pro-apoptotic effects against early stages of colon cancer. 


\section{Acknowledgement}

Financial assistance from the Council of Scientific and Industrial Research (CSIR), Govt. of India (37(1308)/07/EMR-II) is gratefully acknowledged.

\section{References}

1. Gutierrez, J.; Ballinger, S. W.; Darley-Usmar, V. M.; Landar, A. Free radicals, mitochondria, and oxidized lipids: the emerging role in signal transduction in vascular cells, Circ Res, 2006, 99,924-932.

2. Rigas, B.; Sun, Y. Induction of oxidative stress as a mechanism of action of chemopreventive agents against cancer, British J Cancer, 2008, 98,1157-1160.

3. Hundley, T. R.; Rigas, B. Nitric oxidedonating aspirin inhibits colon cancer cell growth via mitogen-activated protein kinase activation, J Pharmacol Exp Ther, 2006, 316,25-34.

4. Williams, J. L.; Nath, N.; Chen, J.; Hundley, T. R.; Gao, J.; Kopelovich, L.; Kashfi, K.; Rigas, B. Growth inhibition of human colon cancer cells by nitric oxide (NO)-donating aspirin is associated with cyclooxygenase-2 induction and beta-catenin/T-cell factor signaling, nuclear factor-kappaB, and $\mathrm{NO}$ synthase 2 inhibition: implications for chemoprevention, Cancer Res, 2003, 63,76137618.

5. Spiegel, A.; Hundley, T. R.; Chen, J.; Gao, J.; Ouyang, N.; Liu, X.; Go, M. F.; Tsioulias, G. J.; Kashfi, K.; Rigas, B. NO-donating aspirin inhibits both the expression and catalytic activity of inducible nitric oxide synthase in HT-29 human colon cancer cells, Biochem Pharmacol, 2005, 70,993-1000.

6. Nath, N.; Kashfi, K.; Chen, J.; Rigas, B. Nitric oxide-donating aspirin inhibits beta-catenin/T cell factor (TCF) signaling in SW480 colon cancer cells by disrupting the nuclear betacatenin-TCF association, Proc Natl Acad Sci, USA, 2003, 100,12584-12589.

7. Rigas, B. Novel agents for cancer prevention based on nitric oxide, Biochemical Society Transactions, 2007, 35(5),1364-1368.
8. Geller, D. A.; de Vera, M. E.; Russell, D. A.; Shapiro, R. A.; Nussler, A. K.; Simmons, R. L.; Billiar, T. R. A central role for interleukin$1 \alpha$ in the in vitro and in vivo regulation of hepatic inducible nitric oxide synthase: IL-1 $\alpha$ induces hepatic nitric oxide synthesis, $J$ Immunol, 1995, 155,4890-4898.

9. Xie, Q. W.; Kashiwabara, Y.; Nathan, C. Role of transcription factor NF- $\mathrm{BB} / \mathrm{Rel}$ in induction of nitric oxide synthase, J Biol Chem, 1994, 269,4705-4708.

10. Spink, J.; Cohen, J.; Evans, T. J. The cytokine responsive vascular smooth muscle cell enhancer of inducible nitric oxide synthase. Activation by nuclear factor- $\kappa \mathrm{B}, J$ Biol Chem, 1995, 270,29541-29547.

11. Makarov, S. S. NF-кB as a therapeutic target in chronic inflammation: recent advances, $\mathrm{Mol}$ Med Today, 2000, 6,441-448.

12. de Martin, R.; Vanhove, B.; Cheng, Q.; Hofer, E.; Csizmadia, V.; Winkler, H.; Bach, F. H. Cytokine-inducible expression in endothelial cells of an I $\kappa \mathrm{B}-\alpha$-like gene is regulated by NF$\kappa \mathrm{B}, E M B O J, 1993,12,2773-2779$.

13. Kaur, J.; Sanyal, S. N. Association of PI3kinase and Wnt signaling in non-steroidal antiinflammatory drug-induced apoptosis in experimental colon cancer, AJBMS, 2009 (in press).

14. Kanwar, S. S.; Vaiphei, K.; Nehru, B.; Sanyal, S. N. Antioxidative effects of non-steroidal anti-inflammatory drugs during the initiation stages of experimental colon carcinogenesis in rats, J Environ Pathol Toxicol Oncol, 2008, 27(2),89-100.

15. Winter, C. A.; Risley, E. A.; Nuss, G. W. Carrageenan induced oedema in hind paw of the rat as an assay of anti-inflammatory drugs, Proc Soc Exp Biol Med, 1962, 111,544-547.

16. Rao, C. V.; Indranie, C.; Simi, B.; Manning, P. T.; Connor, J. R.; Reddy, B. S. Chemopreventive properties of a selective inducible Nitric Oxide synthase inhibitor in colon carcinogenesis, administered alone or in combination with celecoxib, a selective cyclooxygenase- 2 inhibitor, Cancer Res, 2002, 62,65-70.

17. Bradford, M. M. A rapid and sensitive method for the quantitation of microgram quantities of 
protein utilizing the principle of protein-dye binding, Anal Biochem, 1976, 72,248-254.

18. Grossmann, J.; Mohr, S.; Lapetina, E. G.; Fiocchi, C.; Levine, A. D. Sequential and rapid activation of select caspases during apoptosis of normal intestinal epithelial cells, Am J Physiol, 1998, 37,G1117-G1124.

19. LeBel, C. P.; Ischiopoulos, H.; Bondy, S. C. Evaluation of the probe 2,7dichlorofluorescein as indicator of reactive oxygen species formation and oxidative stress, Chem Res Toxicol, 1992, 5,227-231.

20. Stuehr, D. J.; Marletta, M. A. Synthesis of nitrite and nitrate in murine macrophage cell lines, Cancer Res, 1987, 47,5590-5594.

21. Hagos, G. K.; Carroll, R. E.; Kouznetsova, T.; Li, Q.; Toader, V.; Fernandez, P. A.; Swanson, S. M.; Thatcher, G. R. J. Colon cancer chemoprevention by a novel NO chimera that shows anti-inflammatory and antiproliferative activity in vitro and in vivo, Mol Cancer Ther, 2007, 6(8),2230-2239.

22. Steele, V. E.; Wargovich, M. J.; Pereira, M. A.; Rao, C. V.; Lubet, R. A.; Reddy, B. S.; Kellof, G. F. Comparison of the azoxymethane (AOM)-induced rat colon crypt assay with the rat colon tumor assay of cancer chemopreventive agents, Proc Am Assoc Cancer Res, 1999, 40,A377.

23. Benhar, M.; Engelberg, D.; Levitzki, A. ROS, stress-activated kinases and stress signalling in cancer, EMBO Reports, 2002, 3(5),420-425.

24. Jabs, T. Reactive oxygen intermediates as mediators of programmed cell death in plants and animals, Biochem Pharmacol, 1999, 57,231-245.

25. Chung, Y. M.; Bae, Y. S.; Lee, S. Y. Molecular ordering of ROS production, mitochondrial changes, and caspase activation during sodium salicylate induced apoptosis, Free Radic Biol Med, 2003, 34,434-442.

26. Choi, B. M.; Pae, H. O.; Jang, S. I.; Kim, Y. M.; Chung, H. T. Nitric oxide as a proapoptotic as well as anti-apoptotic modulator, J Biochem Mol Biol, 2002, 35(1),116-126.

27. Kim, Y. M.; Chung, H. T.; Simmons, R. L.; Billiar, T. R. Cellular non-heme iron content is a determinant of nitric oxide-mediated apoptosis, necrosis, and caspase inhibition, $J$ Biol Chem, 2000, 275,10954-10961.

28. Brown, G. C.; Borutaite, V. Nitric oxide, cytochrome c and mitochondria, Biochem Soc Symp, 1999, 66,17-25.

29. Tamatani, M.; Ogawa, S.; Niitsu, Y.; Tohyama, M. Involvement of Bcl-2 family and caspase-3-like protease in NO-mediated neuronal apoptosis, J Neurochem, 1998, 71,1588-1596.

30. Asano, K.; Chee, C. B.; Gaston, B.; Lilly, C. M.; Gerard, C.; Drazen, J. M.; Stamler, J. S. Constitutive and inducible nitric oxide synthase gene expression, regulation, and activity in human lung epithelial cells, Proc Natl Acad Sci, USA, 1994, 91,10089-10093.

31. Petros, A.; Bennett, D.; Vallance, P. Effect of nitric oxide synthase inhibitors on hypotension in patients with septic shock, Lancet, 1991, 338,1557-1558.

32. Xie, K.; Huang, S.; Dong, Z.; Juang, S. H.; Gutman, M.; Xie, Q. W.; Nathan, C.; Fidler, I. J. Transfection with the inducible nitric oxide synthase gene suppresses tumorigenicity and abrogates metastasis by K-1735 murine melanoma cells, J Exp Med, 1995, 181,13331343.

33. Xu, W.; Liu, L.; Charles, I. G. Microencapsulated iNOS- expressing cells cause tumor suppression in mice, FASEB J, 2002, 16,213-215.

34. Okada, H.; Mak, T. W. Pathways of apoptotic and non-apoptotic death in tumour cells, Nat Rev Cancer, 2004, 4,592-603.

35. Aggarwal, B. B. Nuclear factor- $\kappa-B$ : the enemy within, Cancer Cell, 2004, 6,203-208.

36. Wu, W. S.; Xu, Z. X.; Hittelman, W. N.; Salomoni, P.; Pandolfi, P. P.; Chang, K. S. Promyelocytic leukemia protein sensitizes tumor necrosis factor $\alpha$-induced apoptosis by inhibiting the NF- $\kappa$ B survival pathway, J Biol Chem, 2003, 278,12294-12304.

37. Shishodia, S.; Aggarwal, B. B. Guggulsterone inhibits $\mathrm{NF}-\kappa \mathrm{B}$ and $\mathrm{I} \kappa \mathrm{B} \alpha$ kinase activation, suppresses expression of anti-apoptotic gene products, and enhances apoptosis, $J$ Biol Chem, 2004, 279,47148-47158. 